\title{
JPCS
}

Peqguruang: Conference Series

Vol. 2 No. 1 Mei 2020

eISSN: 2686-3472

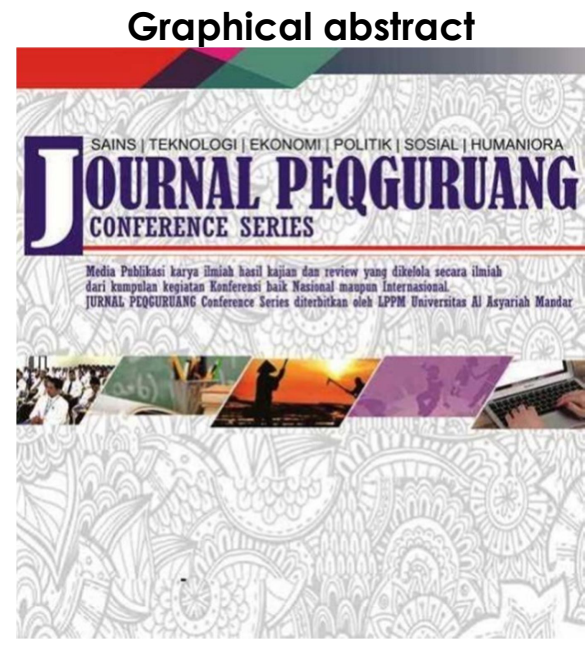

\section{PERANCANGAN SISTEM INFORMASI INVENTORI STOK OBAT STUDI KASUS: APOTEK MITRA MANAKARRA}

\author{
${ }^{1 *}$ Herlina. \\ ${ }^{1}$ Universitas Al Asyariah Mandar. \\ *Corresponding author \\ herlina@mail.unasman.ac.id
}

\begin{abstract}
One of the obstacles experienced by Mitra Manakarra Hospital in managing its pharmacy is that many drugs are detected to be expired in the drug warehouse, this of course results in huge losses for the hospital. The drug stock inventory system is very crucial for a pharmacy, because it can control and determine the level of drug inventory in the warehouse. If the amount of drug inventory is overstocked in large quantities, it can result in idle money and a high risk of damaged (expired) drugs. On the other hand, if there is too little stock of drugs, a stockout will occur and result in a loss of drug sales for hospitals. With the existence of a computer-based Drug Stock Inventory Information System, it will be easier for the pharmacy warehouse to check on stock, so that expired drugs can be controlled. The system is also helpful in making monthly reports, so that reports can be completed on time, and with accurate monthly report information, top level managers can make decisions efficiently regarding drug stocks.
\end{abstract}

Keywords: information system, inventory, pharmacy, drug stock.

\begin{abstract}
Abstrak
Salah satu kendala yang dialami oleh RS Mitra Manakarra dalam tata kelola apoteknya adalah banyak obat yang terdeteksi kadaluarsa (expired) di gudang obat, hal ini tentunya mengakibatkan kerugian besar bagi pihak RS. Sistem inventory stok obat sangat berpengaruh bagi sebuah apotek, sebab dapat mengendalikan dan menentukan tingkat persediaan obat di gudang. Jika jumlah persediaan obat overstock dalam jumlah besar, dapat mengakibatkan modal usaha menjadi menganggur (idle money) serta tingginya resiko kerusakan obat (expired date). Tetapi sebaliknya, jika stok obat terlalu sedikit akan terjadi stockout dan mengakibatkan kerugian penjualan obat bagi rumah sakit. Dengan adanya Sistem Informasi Inventory Stok Obat yang berbasis komputer akan memudahkan pihak gudang apotek untuk melakukan pengecekan stok obat, sehingga obat yang expired dapat terkontrol. Sistem juga sangat membantu dalam pembuatan laporan bulanan, sehingga laporan bisa terselesaikan tepat waktu, dan dengan informasi laporan bulanan yang akurat akan memudahkan level top manager dalam pengambilan keputusan terkait stok obat.
\end{abstract}

Kata kunci: sistem informasi, inventori, apotek, stok obat

Article history

DOI: http://dx.doi.org/10.35329/ip.v2i1.2040

Received : 5 April 2020 | Received in revised form : 15 April 2020 | Accepted : 3 Mei 2020 


\section{PENDAHULUAN}

Rumah Sakit Mitra Manakarra berdiri sejak tahun 2016, menjadi Rumah Sakit Swasta pertama di Kabupaten Mamuju tergolong rumah sakit tipe C dan berhasil menjadi salah satu Rumah Sakit rujukan bagi masyarakat sekabupaten Mamuju. Salah satu pelayanan terbaik yang disediakan oleh RS Mitra Manakarra adalah pelayanan apotek 24 jam.

Salah satu kendala yang dialami oleh RS Mitra Manakarra dalam tata kelola apoteknya adalah banyak obat yang terdeteksi kadaluarsa (expired) di gudang obat, hal ini tentunya mengakibatkan kerugian besar bagi pihak RS. Faktor-faktor penyebab obat menjadi kadaluarsa yaitu : 1) Pengecekan obat yang tidak berkala atau luput di deteksi karena keterbatasan pegawai apotek atau human error, 2) Pembelian atau investasi obat yang berlebihan sementara pola penyakit sering berubah-ubah sehingga menyebabkan stok obat banyak dan menjadi rusak, 3) Kebutuhan pasien yang unpredictable sehingga perputaran obat menjadi lambat.

Sistem pengelolaan persediaan atau biasa dikenal dengan istilah inventory stok obat sangat berpengaruh bagi sebuah apotek. Inventory stok obat dapat mengendalikan dan menentukan tingkat persediaan. Jika jumlah persediaan obat overstock dalam jumlah besar, dapat mengakibatkan modal usaha menjadi menganggur (idle money) serta tingginya resiko kerusakan obat (expired date). Tetapi sebaliknya, jika stok obat terlalu sedikit akan terjadi stockout dan mengakibatkan kerugian penjualan obat bagi rumah sakit.

Selama ini pengolahan data seperti pencatatan obat masuk, obat keluar, dan stok obat apotek masih manual dan konvensional membuat kinerja bagian gudang menjadi kurang efektif dan efisien (Handini W., Muhammad F., 2020).

Karena itu, perlunya managemen persediaan barang saat disimpan untuk digunakan dan dijual pada periode akan datang (Agus R, 2009). Jawabannya adalah pembuatan "Sistem Inventori Stok Obat yang Terkomputerisasi" untuk memudahkan dan memanusiawikan tugas dari pegawai gudang obat di RS Mitra Manakarra. Data yang sudah dikelola kemudian disimpan secara virtual, saling terhubung dan tanpa terjadi pengulangan/redundancy (Muhammad F, 2019)".

Sistem akan memudahkan pengecekan stok obat di gudang sehingga dapat memantau obat yang expired, atau kosong. Selain itu, sistem akan dilengkapi dengan laporan mengenai stok obat di gudang secara otomatis, tentu saja akan sangat memudahkan level top manager karena lebih mudah dalam pengambilan keputusan terkait obat.

\section{METODE PENELITIAN}

Metode yang digunakan untuk pengumpulan data adalah metode kualitatif, dengan tahapan sebagai berikut :

\subsection{Observasi}

Observasi adalah metode terjun langsung ke lapangan dengan mengamati sistem dan kekurangan dari sistem yang berjalan di RS Mitra Manakarra.

\subsection{Wawancara}

Utuk data primer yang tidak dapat diakses melalui observasi maka dilakukan sengan cara wawancara dengan pihak-pihat terkait di RS Mitra manakarra.

Berikut ini adalah tahapan penelitian yang dilakukan, tahapan penelitian bertujuan agar penelitian yang dilaksanakan menjadi terarah dan sistematis (Reza. A, 2016).

\section{HASIL DAN PEMBAHASAN}

\subsubsection{Perancangan Sistem \\ 3.3.1.1 Data Flow Diagram (DFD)}

Data Flow Diagram (DFD) adalah alat yang digunakan untuk menganalisis dan merancang data secara terstruktur, atau dengan kata lain merancang sistem secara visual. Fungsi dari Data Flow Diagram adalah : 1) Sebagai alat pembuatan model yang memungkinkan seorang profesional untuk menggambarkan sistem, 2) Sebagai alat perancangan sistem yang berorientasi alur data digunakan untuk penggambaran analisis dan rancangan sistem.

\subsection{DFD Level 0}

Diagram konteks atau biasa disebut Diagram Level 0 merupakan tingkatan tertinggi dalam DFD, bertujuan untuk menunjukan sistem secara keseluruhan, menggambarkan arus data serta tujuan data yang diproses (Karina H., Yudi P., 2017).

DFD level 0 menggambarkan lingkaran besar yang mewakili seluruh proses dalam suatu sistem, tingkatan ini adalah tingkatan tertinggi dalam DFD.

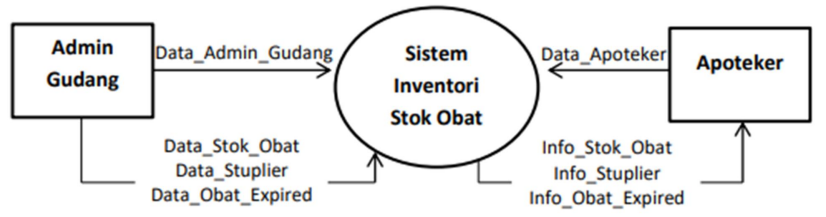

Gambar 1. DFD Level 0 Konteks Diagram Sistem Informasi Stok Obat

\subsection{DFD Level 1}

DFD level 1 merupakan perwakilan lingkaranlingkaran dari satu lingkaran besar, atau sistem yang memecahkan diagram konteks atau DFD level 0. Pada tahap ini, memuat penyimpanan data. 


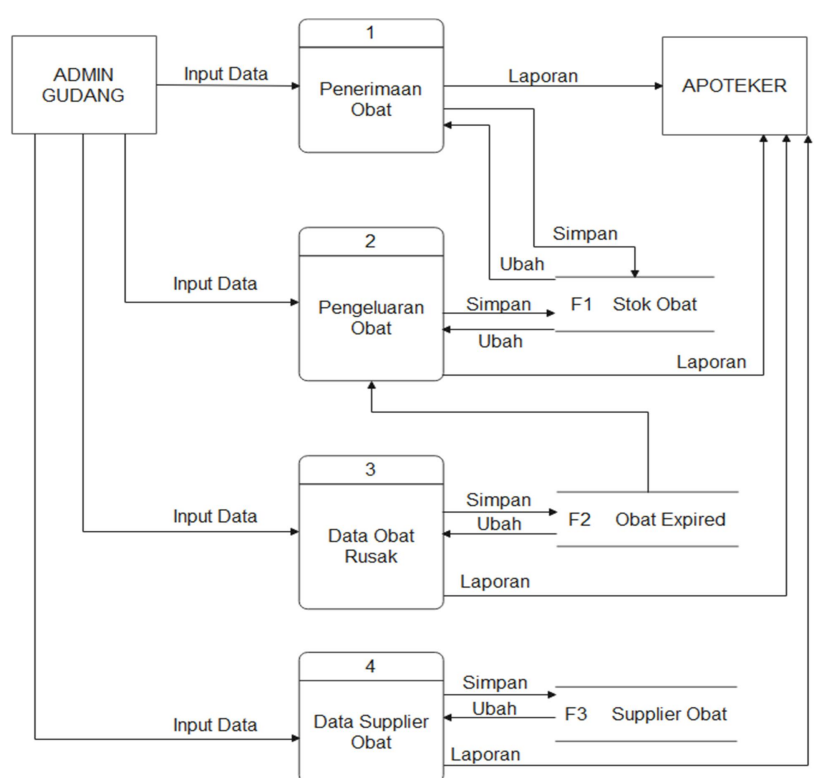

Gambar 2. DFD Level 1

- DFD Level 1 Penerimaan Obat

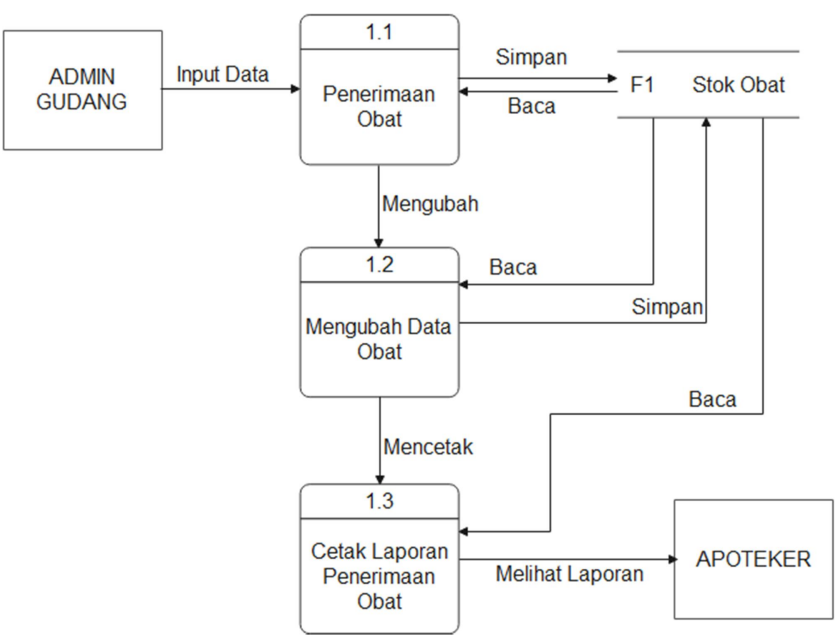

Gambar 3. DFD Level 2

\section{- DFD Level 1 Pengeluaran Obat}

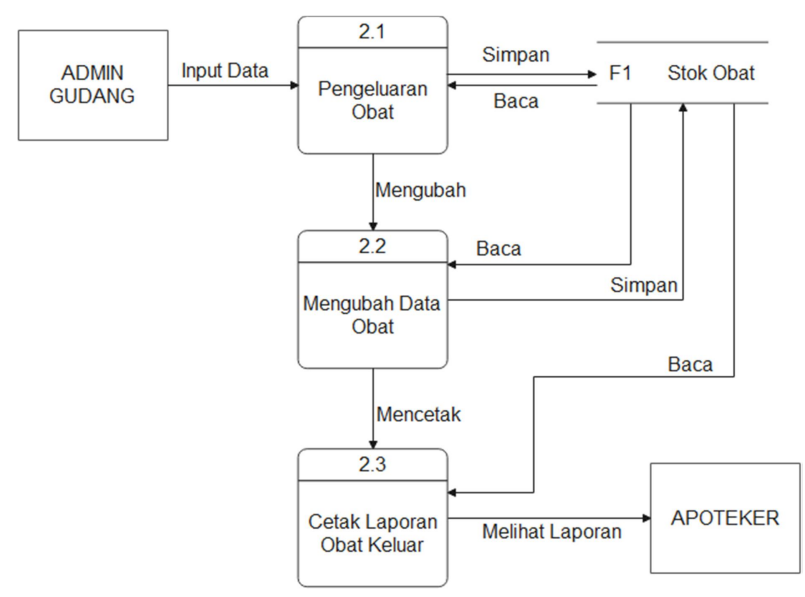

Gambar 4. DFD Level 3
- DFD Level 1 Data Obat Rusak

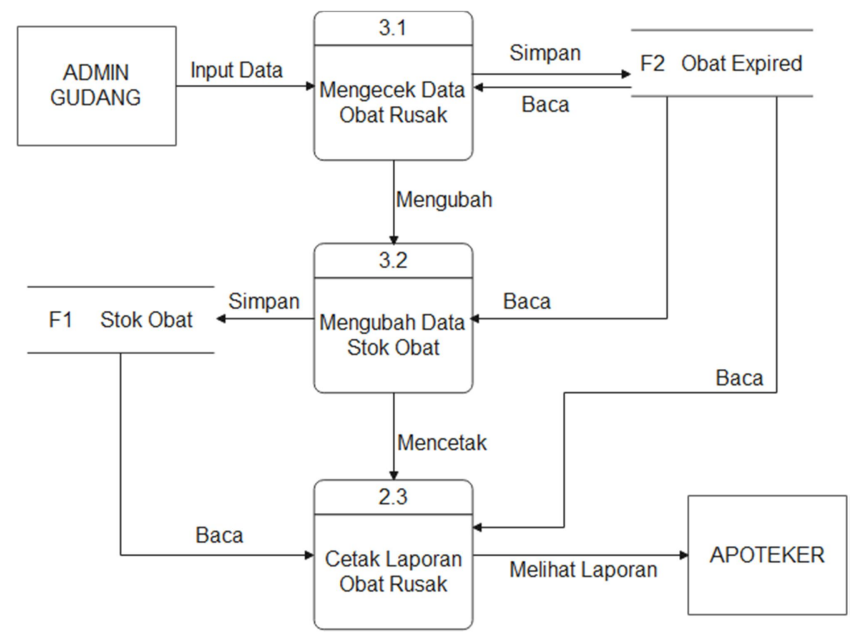

Gambar 5. DFD Level 4

- DFD Level 1 Data Supplier

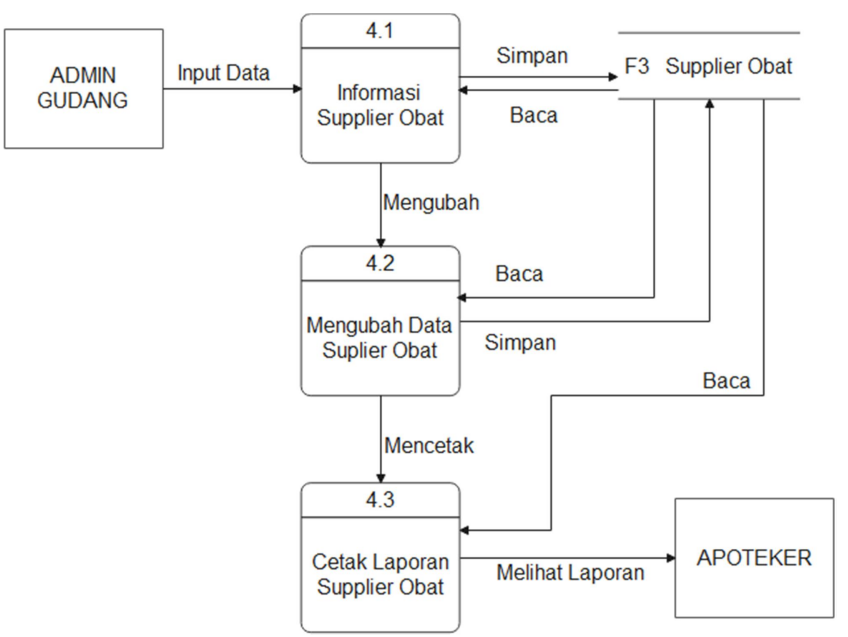

Gambar 6. DFD Level 5

\subsubsection{Entity Relationship Diagram}

Entity Relationship Diagram (ERD) digunakan untuk menggambarkan hubungan antara data yang digunakan dalam sistem. ERD menunjukkan struktur keseluruhan dari kebutuhan data yang diperlukan, ERD data menggunakan simbol entity.

ERD adalah model data yang dikembangkan berdasarkan objek, merepresentasikan grafis dari logika database secara detail (Imam S., dkk, 2018). ERD berisi kumpulan file yang berupa tabel atau arsip yang disimpan dalam media penyimpanan elektronis (Muhammad (M Haidar B., Bramantiyo E. P., 2018). 


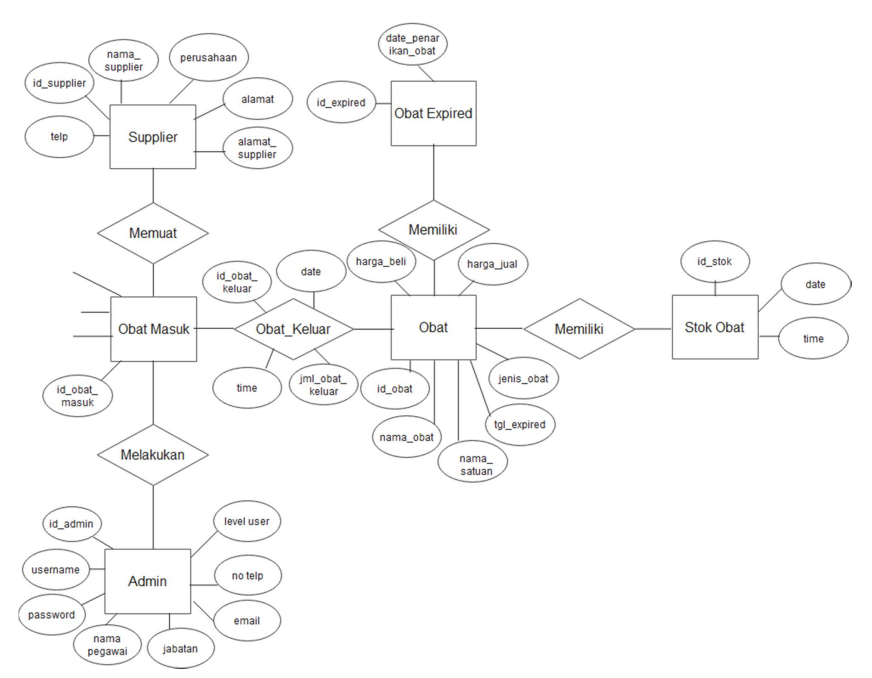

Gambar 7. Entity Relationship Diagram (ERD)

\subsubsection{Perancangan Database Sistem}

Database merupakan kumpulan data-data yang saling berelasi satu dengan yang lainnya, dan tersimpan pada perangkat keras komputer. Perangkat lunak (software) berfungs menampilkan dan memanipulasi data tersebut (Mhd B. R., Tedy S., 2014)..

Database adalah kumpulan field-field yang mempunyai kaitanantara satu file dengan field yang lain sehingga membentuk bangunan data untuk menginformasikan kondisi lalulintasdalam bahasa tertentu

\subsubsection{Admin}

Tabel Admin berisi data pengguna yang dapat mengakses sistem.

Tabel 1. Admin

\begin{tabular}{|c|c|c|c|}
\hline No & Kolom & Tipe Data & Lebar Data \\
\hline 1 & Id admin & NUMBER & 10 \\
\hline 2 & Username & VARCHAR2 & 30 \\
\hline 3 & Password & VARCHAR2 & 256 \\
\hline 4 & Nama_pegawai & VARCHAR2 & 256 \\
\hline 5 & Jabatan & VARCHAR2 & 50 \\
\hline 6 & Email & VARCHAR2 & 100 \\
\hline 7 & No_telp & NUMBER & 12 \\
\hline 8 & Lever_user & NUMBER & 5 \\
\hline
\end{tabular}

\subsubsection{Supplier}

Tabel Supplier berisi data supplier obat yang memasukkan obat ke apotek.

Tabel 2. Supplier

\begin{tabular}{|c|c|c|c|}
\hline No & Kolom & Tipe Data & Lebar Data \\
\hline 1 & Id_supplier & NUMBER & 10 \\
\hline 2 & Nama_supplier & VARCHAR2 & 30 \\
\hline 3 & Nama_perusahaan & VARCHAR2 & 30 \\
\hline 4 & Telp & NUMBER & 12 \\
\hline 5 & Alamat & VARCHAR2 & 30 \\
\hline 6 & Alamat kantor & VARCHAR2 & 30 \\
\hline
\end{tabular}

\subsubsection{Obat}

Tabel Obat berisi data-data obat yang ada di apotek.

Tabel 3. Obat

\begin{tabular}{|c|l|l|c|}
\hline No & Kolom & Tipe Data & Lebar Data \\
\hline 1 & Id_obat & NUMBER & 10 \\
\hline 2 & Nama_obat & VARCHAR2 & 30 \\
\hline 3 & Nama_satuan & VARCHAR2 & 30 \\
\hline 4 & Jenis_obat & VARCHAR2 & 30 \\
\hline 5 & Tgl_expired & DATE & \\
\hline 6 & Harga_beli & INTEGER & \\
\hline 7 & Harga_jual & INTEGER & \\
\hline
\end{tabular}

\subsubsection{Stok Obat}

Tabel Stok Obat berisi data stok obat yang ada di gudang apotek.

Tabel 4. Stok Obat

\begin{tabular}{|c|l|c|c|}
\hline No & \multicolumn{1}{|c}{ Kolom } & Tipe Data & Lebar Data \\
\hline 1 & Id_stok & NUMBER & 10 \\
\hline 2 & Date & DATE & \\
\hline 3 & Time & TIME & \\
\hline 4 & Id_obat & NUMBER & 10 \\
\hline 5 & Nama_obat & VARCHAR2 & 30 \\
\hline 6 & Tgl_expired & DATE & \\
\hline 7 & Jml_stok_masuk & INTEGER & \\
\hline 8 & Sisa_stok & INTEGER & \\
\hline
\end{tabular}

\subsubsection{Obat Masuk}

Tabel Obat Masuk berisi informasi obat yang masuk ke gudang obat.

Tabel 5. Obat Masuk

\begin{tabular}{|c|l|l|c|}
\hline No & \multicolumn{1}{|c|}{ Kolom } & Tipe Data & Lebar Data \\
\hline 1 & Id_obat_masuk & NUMBER & 10 \\
\hline 2 & Date & DATE & \\
\hline 3 & Time & TIME & \\
\hline 4 & Jml_obat_masuk & INTEGER & \\
\hline 5 & Id_obat & NUMBER & 10 \\
\hline 6 & Nama_obat & VARCHAR2 & 30 \\
\hline 7 & Nama_satuan & VARCHAR2 & 30 \\
\hline 8 & Tgl_expired & DATE & \\
\hline 9 & Harga_beli & INTEGER & \\
\hline 10 & Harga_jual & INTEGER & \\
\hline 11 & Id_supplier & NUMBER & 10 \\
\hline 12 & Nama_supplier & VARCHAR2 & 30 \\
\hline 13 & Perusahaan & VARCHAR2 & 30 \\
\hline
\end{tabular}

\subsubsection{Obat Keluar}

Tabel Obat Keluar berisi informasi data-data obat yang keluar dari gudang apotek.

Tabel 6. Obat Keluar

\begin{tabular}{|c|c|c|c|}
\hline No & Kolom & Tipe Data & Lebar Data \\
\hline 1 & Id obat keluar & NUMBER & 10 \\
\hline 2 & Date & DATE & \\
\hline 3 & Time & TIME & \\
\hline 4 & Jml_obat_keluar & INTEGER & \\
\hline 5 & Id_obat & NUMBER & \\
\hline
\end{tabular}




\begin{tabular}{|c|l|l|l|}
\hline 6 & Nama_obat & VARCHAR2 & 30 \\
\hline 7 & Nama_satuan & VARCHAR2 & 30 \\
\hline 8 & Id user & NUMBER & \\
\hline 9 & Nama_pegawai & VARCHAR2 & 30 \\
\hline 10 & Jabatan & VARCHAR2 & 30 \\
\hline
\end{tabular}

Muhammad F. (2019). Rancang Bangun Sistem Informasi Housekeeping Inventory dengan Metode Waterfall. Jurnal Infortech, Vol 1(1).

\subsubsection{Obat Expired}

Tabel Obat Expired berisi data obat yang sudah expired atau kadaluarsa di gudang apotek.

Tabel 7. Stok Obat

\begin{tabular}{|c|l|c|c|}
\hline No & \multicolumn{1}{|c|}{ Kolom } & Tipe Data & Lebar Data \\
\hline 1 & Id_expired & NUMBER & 10 \\
\hline 2 & Date_penarikan & DATE & \\
\hline 3 & Id_obat & NUMBER & 10 \\
\hline 4 & Tgl_expired & DATE & \\
\hline 5 & Jml_penarikan_obat & INTEGER & \\
\hline
\end{tabular}

\section{SIMPULAN}

Dengan adanya Sistem Informasi Inventory Stok Obat yang berbasis komputer akan memudahkan pihak gudang apotek untuk melakukan pengecekan stok obat, sehingga obat yang expired dapat terkontrol.

Sistem juga sangat membantu dalam pembuatan laporan bulanan, sehingga laporan bisa terselesaikan tepat waktu, dan dengan informasi laporan bulanan yang akurat akan memudahkan level top manager dalam pengambilan keputusan terkait stok obat.

\section{DAFTAR PUSTAKA}

Agus R. (2009). Manajemen Persediaan Edisi 1. Yogyakarta : Graha Ilmu.

Handini W., Muhammad F. (2020). Perancangan Sistem Informasi Inventory Obat. Jurnal Rekayasa PErangkat Lunak Vol 1(1).

Imam S., Muhammad S., Riky A. S. (2018). Sistem Informasi Pendataan Pengunjung Perpustakaan (Studi Kasus : Smkn 1 Palembang). Jurnal Ilmiah Betrik Vol 9(3).

Karina H., Yudi P. (2017). Perancangan Model Data Flow Diagram Untuk Mengukur Kualitas Website Menggunakan Webqual 4.0. Jurnal Sistem Informasi Bisnis Vol 7(1).

M Haidar B., Bramantiyo E. P. (2018). Analisis Perancangan Sistem Informasi Pergudangan Di CV. Karya Nugraha. Jurnal Media Teknik \& Sistem Industri Vol 2(1).

Mhd B. R., Tedy S. (2014). Perancangan Sistem Informasi Inventory Spare Part Elektronik Berbasis Web Php (Studi Cv. Human Global Service Yogyakarta. Jurnal Sarjana Teknik Informatika Vol 2(2).

Reza A., Paramidita N., Panji R., Satria A., Shinta P., Siti M. (2016). Analisis dan Perancangan Sistem Informasi Pelayanan Obat di Apotek Generik. Jurnal Edukasi dan Penelitian Informatika Vol 2(1). 